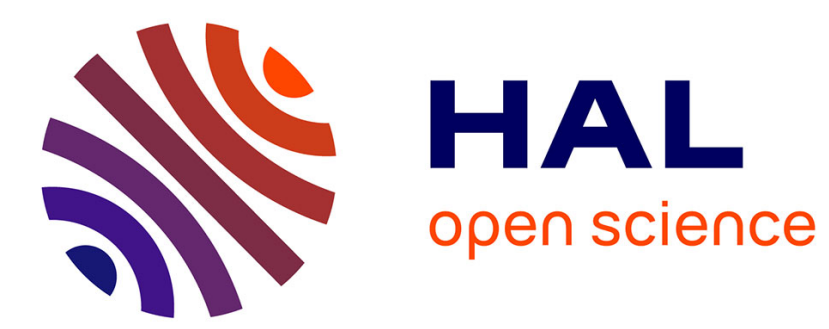

\title{
The many faces of T-type calcium channels
}

\author{
R.C. Lambert, Thomas Bessaïh, Vincenzo Crunelli, Nathalie Leresche
}

\section{To cite this version:}

R.C. Lambert, Thomas Bessaïh, Vincenzo Crunelli, Nathalie Leresche. The many faces of T-type calcium channels. Pflügers Archiv European Journal of Physiology, 2014, 466 (3), pp.415-423. 10.1007/s00424-013-1353-6 . hal-01373454

\section{HAL Id: hal-01373454 \\ https://hal.science/hal-01373454}

Submitted on 28 Sep 2016

HAL is a multi-disciplinary open access archive for the deposit and dissemination of scientific research documents, whether they are published or not. The documents may come from teaching and research institutions in France or abroad, or from public or private research centers.
L'archive ouverte pluridisciplinaire HAL, est destinée au dépôt et à la diffusion de documents scientifiques de niveau recherche, publiés ou non, émanant des établissements d'enseignement et de recherche français ou étrangers, des laboratoires publics ou privés. 


\title{
The many faces of T-type calcium channels
}

\author{
Régis C. Lambert ${ }^{1,2, \#}$, Thomas Bessaïh ${ }^{1,2}$, Vincenzo Crunelli ${ }^{3}$, Nathalie Leresche ${ }^{1,2}$ \\ ${ }^{1}$ UMR 7102 CNRS, ${ }^{2}$ UPMC, Université Paris 6, Paris, France, ${ }^{3}$ Neuroscience Division, School of \\ Biosciences, Cardiff University, Cardiff, UK
}

\#Correspondence: R.C. Lambert, UMR7102, CNRS-UPMC, 9 quai saint Bernard, Paris 75005, France (regis.lambert@snv.jussieu.fr)

Key words : T-type channels, Cav3.1, Cav3.2, Cav3.3, burst firing, tonic firing, neuronal excitability, synaptic transmission, dendritic integration.

\begin{abstract}
Since the discovery of low-voltage activated T-type calcium channels in sensory neurons and the initial characterization of their physiological function mainly in inferior olive and thalamic neurons, studies on neuronal T-type currents have predominantly focused on the generation of low-threshold spike (and associated action potential burst firing) which is strictly conditioned by a preceding hyperpolarization. This Ttype current mediated activity has become an archetype of the function of these channels, constraining our view of the potential physiological and pathological roles that they may play in controlling the excitability of single cells and neural networks. However, greatly helped by the recent availability of the first potent and selective antagonists for this class of calcium channels, novel T-type current functions are rapidly being uncovered, including their surprising involvement in neuronal excitability at depolarized membrane potentials and their complex control of dendritic integration and neurotransmitter release. These and other data summarized in this short review clearly indicate a much wider physiological involvement of T-type channels in neuronal activity than previously expected.
\end{abstract}

\section{Introduction}

Low-voltage activated (LVA) $\mathrm{Ca}^{2+}$ currents (T-type) attracted the attention of the neuroscience community at the beginning of the eighties with the identification in inferior olive neurons of a $\mathrm{Ca}^{2+}$-mediated rebound depolarization that followed a transient hyperpolarization [51]. Similar findings were described at the same time in thalamic neurons [39, 40,50], where at hyperpolarized membrane potentials a subthreshold $\mathrm{Ca}^{2+}$ current gives rise to a transient slow depolarization, the so-called low-threshold spike (LTS), which in turns evokes a prototypical high frequency burst of action potentials (Figure 1A \& B). The functional importance of these discoveries was quickly established by work in anesthetized and naturally sleeping animals, which linked LTSs and high-frequency burst firing to the different rhythmic activities displayed by neurons of the thalamocortical circuit during anesthesia and different stages of sleep [21, 25].

In parallel, the canonical biophysical properties of neuronal T-type currents were established in primary sensory neurons $[10,11,31,57]$. Briefly, T-type channels are activated around $-60 \mathrm{mV}$ and generate a transient inward $\mathrm{Ca}^{2+}$ current that is fully inactivated after a few tens of milliseconds (Figure 1C). Holding the neurons at a membrane potential above $-60 \mathrm{mV}$ induces a nearly complete inactivation of the T-type channel population (Figure 1D): thus, a hyperpolarization that allows some channels to recover from inactivation is required before a substantial T-type current can be evoked. Later, different subtypes of T-type currents were 
described in native tissue (see [38] for example), and 3 genes, displaying multiple alternative splicing, are now known to code for the Cav3.1, 3.2 and 3.3 T-type $\mathrm{Ca}^{2+}$ channels $[14,60]$. The different $\mathrm{T}$-type currents generated by these three subtypes share the same basic properties, i.e. low-threshold of activation, transient activation and a nearly complete inactivation at voltages close to the resting membrane potential of many neurons. However, the time courses of activation, inactivation, deactivation, and recovery from inactivation, and the precise activation and inactivation voltage-dependence slightly vary according to the specific Cav3 channel subtype [33, 42, 44, 64]. Importantly, these small biophysical differences have drastic physiological consequences, as shown for example, by a recent study investigating their impact on synaptically evoked LTSs in thalamic neurons [66].

In line with their biophysical properties and following the pioneering physiological works of Llinas and Steriade's groups [21, 39, 40, 50,62], the vast majority of studies on the role of T-type channels have focused on the generation of LTSs (and associated burst firing), which, as mentioned earlier, is strictly conditioned by a preceding transient or tonic hyperpolarization. This, together with the extensive analysis of the role of these currents in rhythmic bursts across the thalamocortical circuit during sleep-related activity, has made the LTS the archetype of T-type channel function and constrained our view of the potential physiological (and pathological) roles that these neuronal channels may play. Of course, the lack of suitable T-type channel antagonists has hampered the discovery of more subtle functional roles for neuronal T-type currents. Thus, the commonly used divalent cation $\mathrm{Ni}^{2+}$ at concentrations that substantially block the $3 \mathrm{~T}$-type channel isoforms also affect high-voltage activated $\mathrm{Ca}^{2+}$ currents [72], while the hypertensive drug, mibefradil, inhibits high-voltage $\mathrm{Ca}^{2+}$ and $\mathrm{Na}^{+}$currents as well as voltage-dependent and ATP-sensitive $\mathrm{K}^{+}$ channels [8, 32, 48, 55, 56, 67]. Undoubtedly, the recent synthesis of piperidine-derivatives, such as 3,5dichloro-N-[1-(2,2-dimethyl-tetrahydro-pyran-4-ylmethyl)-4-fluoro-piperidin-4-ylmethyl]-benzamide (TTA-P2, [63]), which potently and selectively block T-type currents without affecting other voltage-dependent and synaptic currents [26], will further contribute to unravel more subtle (than the LTS), but undoubtedly as important, physiological roles of neuronal T-type currents. In this review we will present some of these new T-type current functions, including the complex control exerted by this current in dendritic integration and neurotransmitter release, and its surprising involvement in neuronal excitability at depolarized membrane potentials.

\section{The T-type current is a major dendritic conductance}

In the nineties, in addition to their well-accepted role as "burst firing generator", dendritic T-type currents were shown to participate to subthreshold excitatory post-synaptic potentials (EPSPs) in neocortical and hippocampal pyramidal neurons $[52,53]$. Since then, electrophysiological recordings, modeling studies and advanced optical techniques to monitor local $\mathrm{Ca}^{2+}$ dynamics have identified the presence of a high-density of T-type channels in the dendritic shaft and/or spines of many neuronal cell types, including thalamocortical $[23,30,68]$ and nucleus reticularis thalami neurons [13, 17, 22, 41], Purkinje [34] and unipolar brush cells [24] of the cerebellum, medium spiny neurons of the striatum [12], and granule cells of the olfactory bulb [27]. Dendritic localization of the T-type channels has been further confirmed by immunofluorescence [16, 49, 54] and electron microscopy $[43,49,59]$ in the neocortex, hippocampus, thalamus, and cerebellum. However, because electrophysiological recordings from distal dendritic compartments are highly challenging, the impact of the T-type current on the local dendritic membrane potential dynamics is still poorly documented. 
Nevertheless, due to their preferential dendritic localization and low-threshold of activation, T-type currents are highly suited to boost EPSP propagation. In a recent paper, Crandall et al., [17]) demonstrated using two-photon $\mathrm{Ca}^{2+}$ imaging in neurons of the nucleus reticularis thalami that stimulation of distal dendrites locally recruits $\mathrm{T}$-type channels and generates a large distal $\mathrm{Ca}^{2+}$ response, even when the LTS and associated burst firing generation was precluded by holding the cell soma at $-60 \mathrm{mV}$. These data clearly suggest that distally located T-type currents amplify afferent inputs and allow the generation of a somatic subthreshold EPSP, thus presumably compensating for the EPSP attenuation that would normally occur along the dendrites due to their passive cable properties. Similar effects should be present in thalamocortical neurons where a large T-type channel dependent $\mathrm{Ca}^{2+}$ entry was recorded in distal dendrites upon focal glutamate application or synaptic stimulation [30].

In thalamic neurons, due to the extremely high-density of T-type channels, synaptic inputs appear to locally trigger a massive T-type channel activation outshining any effect beside EPSP amplification. However, in neurons where the synaptically evoked T-type current is smaller, its effect on the EPSP shape and propagation may be more complex, as local T-type dependent $\mathrm{Ca}^{2+}$ entry can also modulate the activity of other closely located $\mathrm{Ca}^{2+}$-sensitive conductances. Indeed, it was recently shown that in homogenates of rat cerebellum Cav3.2 T-type channels co-immunoprecipitate with the intermediate conductance $\mathrm{Ca}^{2+}$-activated $\mathrm{K}^{+}$channels, $\mathrm{KCa} 3.1$ [29]. These data suggest a functional channel interaction at the nanodomain level that was further confirmed by the recording in outside-out patches from Purkinje cell of a $\mathrm{Ca}^{2+}$-sensitive $\mathrm{K}^{+}$ current that was blocked by either T-type or $\mathrm{KCa} 3.1$ channel antagonists. As a consequence, during parallel fiber activation, the T-type channel mediated $\mathrm{Ca}^{2+}$ entry opens $\mathrm{KCa}^{2} 1 \mathrm{~K}^{+}$channels that in turn accelerate the subthreshold EPSP decay and create a marked after-hyperpolarization, therefore limiting the summation of EPSPs [29]. Along the same line, a growing number of data points to the existence of direct functional interactions between T-type current and either $\mathrm{Ca}^{2+}$-activated or KV4 A-type $\mathrm{K}^{+}$currents $[1,2,19$, 70], which may also have a drastic impact on dendritic integration. Finally, it should be noted that the Cav3.2-KCa3.1 complex was also shown to shape the spontaneous tonic firing of Purkinje cells at depolarized membrane potentials [29]. Therefore, in this cell type, the T-type channel-dependent increase in the EPSP rate of decay does not appear to require a strong preceding hyperpolarization, the condition that is generally assumed to be necessary to any function of the T-type current.

\section{T-type currents participate to both dendritic and axonal synaptic release}

Because of their relatively fast activation and slow deactivation, T-type $\mathrm{Ca}^{2+}$ channels are ideally suited to mediate large $\mathrm{Ca}^{2+}$ entry during brief depolarizing events such as EPSP, or action potential. These short depolarizations strongly activate the channels while inducing little inactivation and the slowly closing channels mediate a strong current upon repolarization [15, 44]. In addition, although well-known for their prominent inactivation, all three T-type $\mathrm{Ca}^{2+}$ channel isoforms show an overlap of their steady-state inactivation and activation curves that give rise to a window current. This current results from a small fraction of T-type channels that remain open in a voltage range close to the resting membrane potentials of CNS neurons [26, 60]. Although the amplitude and voltage-dependency of the window current are difficult to measure experimentally (but see figure 2 in [26]) and are often estimated from the fit of the steady state inactivation and activation curves, the window current is likely present in many neuronal populations where it leads to a stationary $\mathrm{Ca}^{2+}$ influx and a persistent enhancement of intracellular $\mathrm{Ca}^{2+}$ (see below and Figure 1D). Therefore, when localized at synaptic release sites, T-type channels will supply both a tonic and 
transient $\mathrm{Ca}^{2+}$ current generating a component of spontaneous or evoked neurotransmitter exocytosis whose voltage-dependence is close to the resting membrane potential. As already mentioned, T-type channels are highly expressed in dendrites and therefore are good candidates to trigger neurotransmitter release at dendro-dendritic synapses. Although this type of interaction has attracted little attention so far, it has been studied in details at the reciprocal synapse between granule and mitral cells of the olfactory bulb: here, backpropagating action potentials [27] or strong synaptic stimulation [28] induce GABA release triggered by a large $\mathrm{Ca}^{2+}$ entry, predominantly through $\mathrm{T}$-type channels. T-type currents have also been involved in synaptic transmission of the retinal bipolar cells. In these specialized neurons, which release neurotransmitters in response to graded depolarization, $\mathrm{Ca}^{2+}$ imaging and capacitance measurements have shown that neurotransmitter vesicle fusion depends on both $\mathrm{T}$ and L-type $\mathrm{Ca}^{2+}$ channel activation [58].

More recently, two papers have greatly strengthened the hypothesis of a T-type channel involvement in axonal synaptic release [35, 65]. In layer III presynaptic terminals of the entorhinal cortex, electron microscopy reveals that hyperpolarization-activated cyclic nucleotide-gated channels $(\mathrm{HCN})$ are colocalized with Cav3.2 channels. Block of the HCN current increased the frequency of miniature excitatory postsynaptic events in pyramidal neurons, an effect that was blocked by selective T-type channel antagonists [35]. These data suggest that the presence of presynaptic HCN channels depolarizes the synaptic terminal, thereby decreasing $\mathrm{Ca}^{2+}$ entry via presynaptic T-type $\mathrm{Ca}^{2+}$ channel activity and preventing spontaneous glutamate release (see also [3] for another example of T-type current involvement in miniature synaptic potentials). The full role of the T-type current in cortical synaptic transmission remains to be determined, but the work of Tang et al [65] analyzing GABA release from perisomatic-targeting interneurons in the hippocampal CA1 region may suggest an interesting hypothesis. These authors demonstrated the presence of Cav3.1 channels in preterminals of parvalbumin positive axons near, although not in, the active zones. Activation of presynaptic acetylcholine receptors triggered an asynchronous release of GABAergic quanta that transiently decreased pyramidal cell excitability: this effect was drastically reduced by specific T-type current antagonists. Therefore, it appears that the presence of presynaptic T-type channels is a more general feature of excitatory and inhibitory terminals than initially expected. Furthermore, by contrast to the well known G $\beta$-dependent inhibition of the high-voltage activated $\mathrm{Ca}^{2+}$ channels [71], T-type channel activity has seldom been reported to be inhibited by metabotropic receptors [34, 36, 45, 61]. Therefore, T-type channel dependent asynchronous neurotransmitter release may be a privileged mechanism of synaptic transmission when neurons are receiving strong neuromodulatory input.

\section{T-type currents directly contribute to tonic firing and neuronal excitability at depolarized potentials}

The data reviewed so far demonstrate that T-type currents do not only condition burst firing generation via an LTS, but also control both synaptic release and the dynamics of subthreshold EPSPs. Furthermore, a growing number of data clearly indicate that T-type currents also participate to the generation of tonic firing. Thus, in addition to their localization in the dendritic tree and in presynaptic terminals, two-photon imaging has recently shown that T-type channels colocalize with $\mathrm{Na}^{+}$channels in the axon initial segment (AIS) of dorsal cochlear nucleus interneurons, cerebellar Purkinje cells and cortical layer 5 pyramidal neurons [5]. Moreover, restricted applications of T-type channel antagonists to the AIS not only increase action potential threshold and interspike intervals during burst firing, but also decrease the probability of suprathreshold EPSPs to generate a single action potential. Therefore, the T-type current in the AIS contributes both to burst and tonic firing in dorsal cochlear nucleus interneurons. Furthermore, this T-type channel-dependent 
modulation of neuronal firing is under the control of dopamine receptors that, acting via protein kinase C, downregulates the T-type current [4, 6]. Interestingly, dopamine acts specifically on T-type channels located in the AIS without affecting somatodendritic channels. Since AIS T-type channels represent a small fraction of the whole neuronal T-type channel population, no effect of dopamine agonists is observed when recording the whole-cell T-type current [4]. Interestingly, the majority of studies dealing with the spatial cellular location of T-type channels have so far mainly focus on differences in channel subtype or density [22, 23, 41]. However, by highlighting that the modulation of T-type channels can be restricted to a spatial location in addition to a channel subtype, this study on AIS T-type channels stresses the fact that a number of localized T-type current regulations with an important physiological impact may have so far gone undetected in studies that only recorded whole-cell T-type currents.

More surprisingly, the T-type current has been shown not only to participate but also to promote tonic firing in dopaminergic neurons of the subtantia nigra. These neurons display a pacemaker tonic activity in vitro [70], and the frequency and precision of this pacemaker spiking rely on small $\mathrm{Ca}^{2+}$ activated $\mathrm{K}^{+}$channels (SK) that generate a large after-hyperpolarization following each action potential [69]. Pharmacological and biophysical data, obtained using perforated patches to preserve the physiological intracellular $\mathrm{Ca}^{2+}$ dynamics, clearly demonstrated that, during pacemaker tonic firing, $\mathrm{Ca}^{2+}$ entry through $\mathrm{T}$-type channels was responsible for the activation of SK channels. Moreover, application of T-type channel antagonists drastically disrupts the firing regularity and reveals a burst-like pattern in some neurons [70]. Therefore, at least in an in vitro preparation, the T-type current in dopaminergic neurons of the subtantia nigra prevents intrinsic burst firing via its functional coupling with SK channels.

Finally, our recent data in thalamic neurons demonstrate that T-type current effects on cellular excitability do not always require a preceding transient or tonic hyperpolarization. The density of T-type channels expressed in thalamic neurons is especially high resulting in a significant number of deinactivated T-type channels at depolarized potentials (Figure 2A \& B). Moreover, in thalamocortical neurons relaying sensory information, the amplitude of the current generated by this population of deinactivated T-type channels is enhanced by a voltage-dependent phosphorylation process that specifically occurs at these potentials $[7,46]$ (Figure $2 \mathrm{C}$ ). Hence, the combined effect of the phosphorylation-dependent potentiation and high channel density allows the generation of T-type currents at depolarized potentials with two major physiological consequences. First, the window T-type current is large enough (few tens of $p A$ ) to set the resting membrane potential of thalamocortical neurons (Figure 3A) [26]. Moreover, it determines the occurrence, and controls the duration of the UP states of slow $(<1 \mathrm{~Hz})$ oscillations $[9,37]$ (Figure $3 \mathrm{~B}$ ) (for a detailed summary of this mechanism see Fig. 3 in [18]). Second, the significant fraction of T-type channels that is available at depolarized potential participates to EPSP amplification and has a drastic effect on spike probability during tonic firing. Indeed, using TTA-P2 and the dynamic clamp technique, we demonstrated that the activation of T-type channels during wake-like states is a major determinant for single spike occurrence (Figure 4; [20]). Since the T-type current activation and its subsequent boosting of the EPSPs become gradually more prominent with slight hyperpolarization, the range of depolarized membrane potentials where synaptic inputs can reach the spike threshold increases. The key physiological significance of these results is that the recruitment of T-type channels during tonic firing confers a remarkable robustness to the output of thalamocortical neurons [20] and secures information transfer across thalamic networks.

\section{Conclusions and future directions}


The data reviewed above firmly establish that the roles of the T-type $\mathrm{Ca}^{2+}$ current go far beyond their classical function as "burst generators". These novel functions include a key involvement in dendritic physiology, in particular synaptic integration and plasticity as well as dendro-dendritic synaptic release. In addition, in many brain areas, T-type channel have been found to be located in unexpected cellular compartments, such as the AIS and the axonal presynaptic terminals, where the roles of the T-type currents are just beginning to be understood. The discovery of the first potent and selective T-type current antagonists and the availability of knock-out mice for the different isoforms of these channels will greatly help to further decipher new roles in physiological functions and in pathological conditions. At the same time, structure-functions studies are revealing that T-type currents can be modulated by a number of intracellular pathways, whose physiological impacts on single cell and neural network excitability remain to be investigated in details. Furthermore, based on these molecular data and tools, direct interactions between Ttype channels and other proteins, including ionic channels, have been established, suggesting that a diversity of localized T-type current functions and regulations may still need to be elucidated. Finally, from the time of their discovery it has been assumed that in the vast majority of neuronal types the generation of an LTS (and associated burst firing) was the only physiological role of $\mathrm{T}$-type $\mathrm{Ca}^{2+}$ channels, since their nearly complete inactivation around the resting membrane potential should preclude their involvement in single action potential firing. However, it is now clearly established that, at least in thalamic neurons, the high density of T-type channels, and/or their regulatory mechanisms, ensure that a component of the T-type $\mathrm{Ca}^{2+}$ current is available at depolarized membrane potentials where it may play a major role in controlling neuronal excitability during activities related to the awake state.

\section{Aknowledgements}

Our work in this field was supported by CNRS LEA528, Agence Nationale de la Recherche 06-Neuro, Agence Nationale de la Recherche MNMP 2009, the Wellcome Trust (grants 71436, 78403, 91882).

\section{References}

1. Anderson D, Engbers JD, Heath NC, Bartoletti TM, Mehaffey WH, Zamponi GW, Turner RW (2013) The Cav3-Kv4 complex acts as a calcium sensor to maintain inhibitory charge transfer during extracellular calcium fluctuations. The Journal of neuroscience : the official journal of the Society for Neuroscience 33:7811-24

2. Anderson D, Mehaffey WH, Iftinca M, Rehak R, Engbers JD, Hameed S, Zamponi GW, Turner RW (2010) Regulation of neuronal activity by Cav3-Kv4 channel signaling complexes. Nature neuroscience 13:333-7

3. Bao J, Li JJ, Perl ER (1998) Differences in Ca2+ channels governing generation of miniature and evoked excitatory synaptic currents in spinal laminae I and II. The Journal of neuroscience : the official journal of the Society for Neuroscience 18:8740-50

4. Bender KJ, Ford CP, Trussell LO (2010) Dopaminergic modulation of axon initial segment calcium channels regulates action potential initiation. Neuron 68:500-11 DOI Electronic Resource Number

5. Bender KJ, Trussell LO (2009) Axon initial segment Ca2+ channels influence action potential generation and timing. Neuron 61:259-71

6. Bender KJ, Uebele VN, Renger JJ, Trussell LO (2012) Control of firing patterns through modulation of axon initial segment T-type calcium channels. The Journal of physiology 590:109-18

7. Bessaih T, Leresche N, Lambert RC (2008) T current potentiation increases the occurrence and temporal fidelity of synaptically evoked burst firing in sensory thalamic neurons. Proceedings of the National Academy of Sciences of the United States of America 105:11376-81

8. Bezprozvanny I, Tsien RW (1995) Voltage-dependent blockade of diverse types of voltage-gated Ca2+ channels expressed in Xenopus oocytes by the Ca2+ channel antagonist mibefradil (Ro 40-5967). Molecular pharmacology 48:540-9

9. Blethyn KL, Hughes SW, Tóth TI, Cope DW, Crunelli V (2006) Neuronal basis of the slow $(<1 \mathrm{~Hz})$ oscillation in neurons of the nucleus reticularis thalami in vitro. J Neurosci $26: 2474-86$ 
10. Bossu JL, Feltz A (1986) Inactivation of the low-threshold transient calcium current in rat sensory neurones: evidence for a dual process. J Physiol 376:341-57

11. Carbone E, Lux HD (1984) A low voltage-activated, fully inactivating Ca channel in vertebrate sensory neurones. Nature 310:501-2

12. Carter AG, Sabatini BL (2004) State-dependent calcium signaling in dendritic spines of striatal medium spiny neurons. Neuron 44:483-93

13. Chausson P, Leresche N, Lambert RC (2013) Dynamics of Intrinsic Dendritic Calcium Signaling during Tonic Firing of Thalamic Reticular Neurons. PloS one 8:e72275

14. Chemin J, Monteil A, Bourinet E, Nargeot J, Lory P (2001) Alternatively spliced alpha(1G) $(\mathrm{Ca}(\mathrm{V}) 3.1)$ intracellular loops promote specific T-type $\mathrm{Ca}(2+)$ channel gating properties. Biophys $\mathrm{J}$ 80:1238-50

15. Chemin J, Monteil A, Perez-Reyes E, Bourinet E, Nargeot J, Lory P (2002) Specific contribution of human T-type calcium channel isotypes (alpha(1G), alpha(1H) and alpha(1I)) to neuronal excitability. $J$ Physiol 540:3-14.

16. Craig PJ, Beattie RE, Folly EA, Banerjee MD, Reeves MB, Priestley JV, Carney SL, Sher E, PerezReyes E, Volsen SG (1999) Distribution of the voltage-dependent calcium channel alpha1G subunit mRNA and protein throughout the mature rat brain. Eur J Neurosci 11:2949-64.

17. Crandall SR, Govindaiah G, Cox CL (2010) Low-threshold Ca2+ current amplifies distal dendritic signaling in thalamic reticular neurons. The Journal of neuroscience : the official journal of the Society for Neuroscience 30:15419-29

18. Crunelli V, Toth TI, Cope DW, Blethyn K, Hughes SW (2005) The 'window' T-type calcium current in brain dynamics of different behavioural states. The Journal of physiology 562:121-9

19. Cueni L, Canepari M, Lujan R, Emmenegger Y, Watanabe M, Bond CT, Franken P, Adelman JP, Luthi A (2008) T-type Ca2+ channels, SK2 channels and SERCAs gate sleep-related oscillations in thalamic dendrites. Nature neuroscience 11:683-92

20. Deleuze C, David F, Behuret S, Sadoc G, Shin HS, Uebele VN, Renger JJ, Lambert RC, Leresche N, Bal $T$ (2012) T-type calcium channels consolidate tonic action potential output of thalamic neurons to neocortex. The Journal of neuroscience : the official journal of the Society for Neuroscience 32:12228-36

21. Deschenes M, Paradis M, Roy JP, Steriade M (1984) Electrophysiology of neurons of lateral thalamic nuclei in cat: resting properties and burst discharges. J Neurophysiol 51:1196-219

22. Destexhe A, Contreras D, Steriade M, Sejnowski TJ, Huguenard JR (1996) In vivo, in vitro, and computational analysis of dendritic calcium currents in thalamic reticular neurons. J Neurosci 16:169-85

23. Destexhe A, Neubig M, Ulrich D, Huguenard J (1998) Dendritic low-threshold calcium currents in thalamic relay cells. J Neurosci 18:3574-88

24. Diana MA, Otsu Y, Maton G, Collin T, Chat M, Dieudonne S (2007) T-type and L-type Ca2+ conductances define and encode the bimodal firing pattern of vestibulocerebellar unipolar brush cells. The Journal of neuroscience : the official journal of the Society for Neuroscience 27:3823-38

25. Domich L, Oakson G, Steriade M (1986) Thalamic burst patterns in the naturally sleeping cat: a comparison between cortically projecting and reticularis neurones. J Physiol (Lond) 379:429-49

26. Dreyfus FM, Tscherter A, Errington AC, Renger JJ, Shin HS, Uebele VN, Crunelli V, Lambert RC, Leresche N (2010) Selective T-type calcium channel block in thalamic neurons reveals channel redundancy and physiological impact of I(T)window. The Journal of neuroscience : the official journal of the Society for Neuroscience 30:99-109

27. Egger V, Svoboda K, Mainen ZF (2003) Mechanisms of lateral inhibition in the olfactory bulb: efficiency and modulation of spike-evoked calcium influx into granule cells. The Journal of neuroscience : the official journal of the Society for Neuroscience 23:7551-8

28. Egger V, Svoboda K, Mainen ZF (2005) Dendrodendritic synaptic signals in olfactory bulb granule cells: local spine boost and global low-threshold spike. The Journal of neuroscience : the official journal of the Society for Neuroscience 25:3521-30

29. Engbers JD, Anderson D, Asmara H, Rehak R, Mehaffey WH, Hameed S, McKay BE, Kruskic M, Zamponi GW, Turner RW (2012) Intermediate conductance calcium-activated potassium channels modulate summation of parallel fiber input in cerebellar Purkinje cells. Proceedings of the National Academy of Sciences of the United States of America 109:2601-6

30. Errington AC, Renger JJ, Uebele VN, Crunelli V (2010) State-dependent firing determines intrinsic dendritic Ca2+ signaling in thalamocortical neurons. J Neurosci 30:14843-53

31. Fedulova SA, Kostyuk PG, Veselovsky NS (1985) Two types of calcium channels in the somatic membrane of new-born rat dorsal root ganglion neurones. The Journal of physiology 359:431-46

32. Gomora JC, Enyeart JA, Enyeart JJ (1999) Mibefradil potently blocks ATP-activated K(+) channels in adrenal cells. Molecular pharmacology $56: 1192-7$

33. Hering J, Feltz A, Lambert RC (2004) Slow inactivation of the Ca(V)3.1 isotype of T-type calcium channels. J Physiol 555:331-44

34. Hildebrand ME, Isope P, Miyazaki T, Nakaya T, Garcia E, Feltz A, Schneider T, Hescheler J, Kano M, Sakimura K, Watanabe M, Dieudonne S, Snutch TP (2009) Functional coupling between mGluR1 and Cav3.1 T-type calcium channels contributes to parallel fiber-induced fast calcium signaling within Purkinje 
cell dendritic spines. The Journal of neuroscience : the official journal of the Society for Neuroscience 29:9668-82

35. Huang Z, Lujan R, Kadurin I, Uebele VN, Renger JJ, Dolphin AC, Shah MM (2011) Presynaptic HCN1 channels regulate Cav3.2 activity and neurotransmission at select cortical synapses. Nature neuroscience 14:478-86

36. Huc S, Monteil A, Bidaud I, Barbara G, Chemin J, Lory P (2009) Regulation of T-type calcium channels: signalling pathways and functional implications. Biochimica et biophysica acta 1793:947-52

37. Hughes SW, Cope DW, Blethyn KL, Crunelli V (2002) Cellular mechanisms of the slow $(1 \mathrm{~Hz})$ oscillation in thalamocortical neurons in vitro. Neuron 33:947-58.

38. Huguenard JR, Prince DA (1992) A novel T-type current underlies prolonged $\mathrm{Ca}(2+)$-dependent burst firing in GABAergic neurons of rat thalamic reticular nucleus. J Neurosci 12:3804-17

39. Jahnsen H, Llinas R (1984) Electrophysiological properties of guinea-pig thalamic neurones: an in vitro study. J Physiol 349:205-26

40. Jahnsen H, Llinas R (1984) lonic basis for the electro-responsiveness and oscillatory properties of guinea-pig thalamic neurones in vitro. J Physiol 349:227-47

41. Joksovic PM, Bayliss DA, Todorovic SM (2005) Different kinetic properties of two T-type Ca2+ currents of rat reticular thalamic neurones and their modulation by enflurane. The Journal of physiology 566:12542

42. Klockner U, Lee JH, Cribbs LL, Daud A, Hescheler J, Pereverzev A, Perez-Reyes E, Schneider T (1999) Comparison of the $\mathrm{Ca} 2+$ currents induced by expression of three cloned alpha1 subunits, alpha1G, alpha1 $\mathrm{H}$ and alpha1l, of low-voltage-activated T-type Ca2+ channels. The European journal of neuroscience 11:4171-8

43. Kovacs K, Sik A, Ricketts C, Timofeev I (2010) Subcellular distribution of low-voltage activated T-type $\mathrm{Ca} 2+$ channel subunits $(\mathrm{Ca}(\mathrm{v}) 3.1$ and $\mathrm{Ca}(\mathrm{v}) 3.3)$ in reticular thalamic neurons of the cat. Journal of neuroscience research 88:448-60

44. Kozlov AS, McKenna F, Lee JH, Cribbs LL, Perez-Reyes E, Feltz A, Lambert RC (1999) Distinct kinetics of cloned T-type $\mathrm{Ca} 2+$ channels lead to differential $\mathrm{Ca} 2+$ entry and frequency-dependence during mock action potentials. Eur J Neurosci 11:4149-58.

45. Lambert RC, Bessaih T, Leresche N (2006) Modulation of neuronal T-type calcium channels. CNS \& neurological disorders drug targets 5:611-27

46. Leresche N, Hering J, Lambert RC (2004) Paradoxical potentiation of neuronal T-type Ca2+ current by ATP at resting membrane potential. J Neurosci 24:5592-602

47. Leresche N, Lightowler S, Soltesz I, Jassik-Gerschenfeld D, Crunelli V (1991) Low-frequency oscillatory activities intrinsic to rat and cat thalamocortical cells. J Physiol (Lond) 441:155-74

48. Liu JH, Bijlenga P, Occhiodoro T, Fischer-Lougheed J, Bader CR, Bernheim L (1999) Mibefradil (Ro 405967) inhibits several $\mathrm{Ca} 2+$ and $\mathrm{K}+$ currents in human fusion-competent myoblasts. British journal of pharmacology 126:245-50

49. Liu XB, Murray KD, Jones EG (2011) Low-threshold calcium channel subunit $\mathrm{Ca}(\mathrm{v}) 3.3$ is specifically localized in GABAergic neurons of rodent thalamus and cerebral cortex. The Journal of comparative neurology 519:1181-95

50. Llinas R, Jahnsen H (1982) Electrophysiology of mammalian thalamic neurones in vitro. Nature 297:4068

51. Llinas R, Yarom Y (1981) Electrophysiology of mammalian inferior olivary neurones in vitro. Different types of voltage-dependent ionic conductances. J Physiol 315:549-67

52. Magee JC, Johnston D (1995) Synaptic activation of voltage-gated channels in the dendrites of hippocampal pyramidal neurons. Science $268: 301-4$

53. Markram H, Sakmann B (1994) Calcium transients in dendrites of neocortical neurons evoked by single subthreshold excitatory postsynaptic potentials via low-voltage-activated calcium channels. Proc Natl Acad Sci U S A 91:5207-11

54. McKay BE, McRory JE, Molineux ML, Hamid J, Snutch TP, Zamponi GW, Turner RW (2006) Ca(V)3 Ttype calcium channel isoforms differentially distribute to somatic and dendritic compartments in rat central neurons. The European journal of neuroscience 24:2581-94

55. Mishra SK, Hermsmeyer K (1994) Selective inhibition of T-type Ca2+ channels by Ro 40-5967. Circulation research 75:144-8

56. Nilius B, Prenen J, Kamouchi M, Viana F, Voets T, Droogmans G (1997) Inhibition by mibefradil, a novel calcium channel antagonist, of $\mathrm{Ca}(2+)$ - and volume-activated $\mathrm{Cl}$ - channels in macrovascular endothelial cells. British journal of pharmacology 121:547-55

57. Nowycky MC, Fox AP, Tsien RW (1985) Three types of neuronal calcium channel with different calcium agonist sensitivity. Nature 316:440-3

58. Pan ZH, Hu HJ, Perring P, Andrade R (2001) T-type $\mathrm{Ca}(2+)$ channels mediate neurotransmitter release in retinal bipolar cells. Neuron 32:89-98 
59. Parajuli LK, Fukazawa Y, Watanabe M, Shigemoto R (2010) Subcellular distribution of alpha1G subunit of T-type calcium channel in the mouse dorsal lateral geniculate nucleus. The Journal of comparative neurology 518:4362-74

60. Perez-Reyes E (2003) Molecular physiology of low-voltage-activated t-type calcium channels. Physiol Rev 83:117-61

61. Perez-Reyes E (2010) G protein-mediated inhibition of Cav3.2 T-type channels revisited. Molecular pharmacology $77: 136-8$

62. Roy JP, Clercq M, Steriade M, Deschenes M (1984) Electrophysiology of neurons of lateral thalamic nuclei in cat: mechanisms of long-lasting hyperpolarizations. J Neurophysiol 51:1220-35

63. Shipe WD, Barrow JC, Yang ZQ, Lindsley CW, Yang FV, Schlegel KA, Shu Y, Rittle KE, Bock MG, Hartman GD, Tang C, Ballard JE, Kuo Y, Adarayan ED, Prueksaritanont T, Zrada MM, Uebele VN, Nuss CE, Connolly TM, Doran SM, Fox SV, Kraus RL, Marino MJ, Graufelds VK, Vargas HM, Bunting PB, Hasbun-Manning M, Evans RM, Koblan KS, Renger JJ (2008) Design, synthesis, and evaluation of a novel 4-aminomethyl-4-fluoropiperidine as a T-type Ca2+ channel antagonist. J Med Chem 51:3692-5

64. Talavera K, Nilius B (2006) Biophysics and structure-function relationship of T-type Ca2+ channels. Cell Calcium 40:97-114

65. Tang AH, Karson MA, Nagode DA, McIntosh JM, Uebele VN, Renger JJ, Klugmann M, Milner TA, Alger BE (2011) Nerve terminal nicotinic acetylcholine receptors initiate quantal GABA release from perisomatic interneurons by activating axonal T-type $(\mathrm{Cav} 3) \mathrm{Ca}(2)(+)$ channels and $\mathrm{Ca}(2)(+)$ release from stores. The Journal of neuroscience : the official journal of the Society for Neuroscience 31:13546-61

66. Tscherter A, David F, Ivanova T, Deleuze C, Renger JJ, Uebele VN, Shin HS, Bal T, Leresche N, Lambert RC (2011) Minimal alterations in T-type calcium channel gating markedly modify physiological firing dynamics. The Journal of physiology 589:1707-24

67. Viana F, Van den Bosch L, Missiaen L, Vandenberghe W, Droogmans G, Nilius B, Robberecht W (1997) Mibefradil (Ro 40-5967) blocks multiple types of voltage-gated calcium channels in cultured rat spinal motoneurones. Cell Calcium 22:299-311

68. Williams SR, Stuart GJ (2000) Action potential backpropagation and somato-dendritic distribution of ion channels in thalamocortical neurons. J Neurosci 20:1307-17

69. Wolfart J, Neuhoff H, Franz O, Roeper J (2001) Differential expression of the small-conductance, calcium-activated potassium channel SK3 is critical for pacemaker control in dopaminergic midbrain neurons. The Journal of neuroscience : the official journal of the Society for Neuroscience 21:3443-56

70. Wolfart J, Roeper J (2002) Selective coupling of T-type calcium channels to SK potassium channels prevents intrinsic bursting in dopaminergic midbrain neurons. The Journal of neuroscience : the official journal of the Society for Neuroscience 22:3404-13

71. Zamponi GW (2001) Determinants of G protein inhibition of presynaptic calcium channels. Cell biochemistry and biophysics 34:79-94

72. Zamponi GW, Bourinet E, Snutch TP (1996) Nickel block of a family of neuronal calcium channels: subtype- and subunit-dependent action at multiple sites. The Journal of membrane biology 151:77-90

\section{Figure legends}

Figure 1: Generation of LTS and voltage-dependence of the T-type calcium current in thalamocortical neurons.

A. Voltage-dependence of the T-type current mediated low frequency oscillations in a thalamocortical neuron. Note that rhythmic LTSs crowned by high-frequency bursts of action potentials occur in a narrow range of membrane potential around $-65 \mathrm{mV}$. Modified with permission from [47].

B. Synaptically evoked LTSs. In a thalamocortical neuron maintained at $-70 \mathrm{mV}$, an EPSP evoked by stimulation of the sensory afferents activates T-type channels leading to the generation of a LTS crowned by a high frequency burst of action potentials (left trace). In the same neuron at a holding potential where T-type channels are inactivated $(-60 \mathrm{mV})$, a rebound LTS is induced following a GABA mediated IPSP that allows some T-type channels to recover from inactivation (right trace). An enlargement of the LTS is presented in inset. Modified with permission from [26].

C. T-type currents (bottom traces) evoked from a holding potential of $-100 \mathrm{mV}$ in response to depolarizing current steps of increasing intensity (first step: $-70 \mathrm{mV}$; step: $2.5 \mathrm{mV}$; top traces).

D. Activation and steady-state inactivation curves. The activation curve (filled circles) is constructed from the 
peak current amplitude of the currents presented in C. For the steady-state inactivation curve (empty circles), the channel availability is estimated from the current amplitude measured at $-50 \mathrm{mV}$ as a function of a $2 \mathrm{~s}$ conditioning prepulse from $-100 \mathrm{mV}$ to $-60 \mathrm{mV}$. Note the low voltage of activation of the T-type channels and their nearly complete inactivation at around $-60 \mathrm{mV}$. Note also the overlap of the activation and inactivation curves that allow the presence of a window current. The voltage-dependence of the window current, centered around $-60 \mathrm{mV}$, estimated by multiplying the fits of the steady-state inactivation and activation curves, is illustrated in inset.

Figure 2: The high channel density and a phosphorylation-dependent potentiation facilitate the generation of T-type currents at depolarized membrane potentials in thalamocortical neurons

A. In the presence of TTX, rebound LTSs were evoked in a thalamocortical neuron on the offset of variable transient hyperpolarizations to $-80 \mathrm{mV}$ that induced partial recovery of the T-type channels from inactivation. Note that maximal LTSs were already evoked with $300 \mathrm{~ms}$-long hyperpolarization at $-80 \mathrm{mV}$ although the recovery from inactivation of the whole T-type channel population would have required at least a $1 \mathrm{~s}$ hyperpolarization at $-100 \mathrm{mV}$. Modified with permission from [7].

B. In a thalamocortical neuron maintained at $-60 \mathrm{mV}$, rebound LTSs were evoked by stimulations of GABAergic afferents in control condition and when $50 \%$ of the T-channels population is blocked using $20 \mathrm{nM}$ TTA-P2 (see ref [25] for more details). This massive reduction in T-type channel availability did not have any effect on the amplitude of the LTS or the number of action potentials in the burst, but only delayed the start of the LTS. Modified with permission from [26].

C. Schematic representation of the mechanisms underlying T-type current potentiation. Left panel: At depolarized membrane potential, inactivated T-type channels are phosphorylated. During a short hyperpolarization the channels that recover from inactivation and enter the closed state are still phosphorylated. Activation of these phosphorylated channels generates a large amplitude T-type current. Right panel: After prolonged hyperpolarization, the closed T-type channels are de-phosphorylated and their activation generates a current of smaller amplitude.

Figure 3: Window T-type current contributes to neuronal excitability of thalamocortical neurons.

A. Contribution of the window T-type current to the resting membrane potential. Block of T-type channels with TTA-P2 induced a clear hyperpolarization in thalamocortical neurons held at $-60 \mathrm{mV}$ (potential corresponding to the peak amplitude of the window current) but not at $-70 \mathrm{mV}$ where the window current is of minimal amplitude (see figure 1D).

B. Progressive block of the T-type channel population induced a gradual modification of the intrinsic slow oscillations in thalamocortical neuron. Starting from a slow $(<1 \mathrm{~Hz})$ oscillation (a), application of TTA-P2 progressively decreased the duration of the slow oscillation UP state (b \& c) that was then abolished after a few additional minutes of drug exposure. Modified with permission from [26].

Figure 4: T-type current boosts stimulus-evoked firing at depolarized membrane potentials and confers robustness to the neuronal response across a large range of membrane potentials.

A. Spike raster plots of a thalamocortical neuron injected with gAMPA of fixed amplitude following a $10 \mathrm{~Hz}$ Poisson distribution (bottom trace) and continuously submitted to synaptic excitatory and inhibitory noise. Using the dynamic clamp technique, the same sequences of gAMPA and excitatory/inhibitory noise were 
injected in control condition and when the T-type channels are blocked by TTA-P2. The neuron was successively maintained at mean membrane potentials of $-60,-65$, and $-70 \mathrm{mV}$. The intracellular activities recorded during the time window indicated by the black line in $A$ are illustrated in $B$. The consistent decrease in the number of spikes in the presence of TTA-P2 compared with the control condition demonstrates the contribution of T-type channels to the firing probability at depolarized potentials $(-60 \mathrm{mV})$. In addition, note that the firing probability was barely affected by membrane potential changes in the control condition while it was decreased upon hyperpolarization in the presence of TTA-P2. Modified with permission from [20]. 
Figure 1

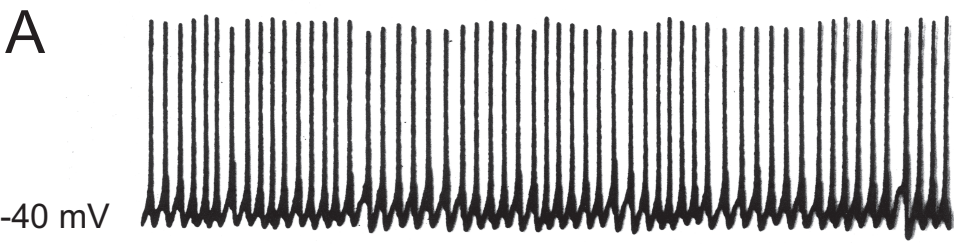

C

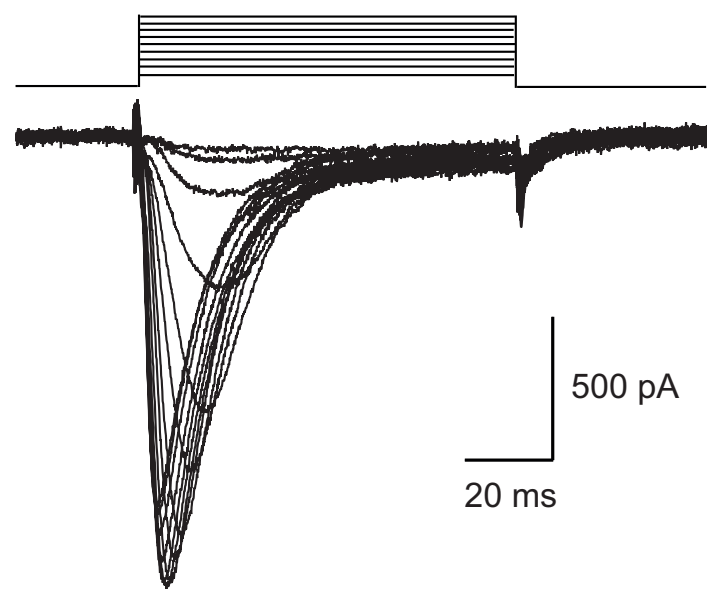

-75
B

$-65$
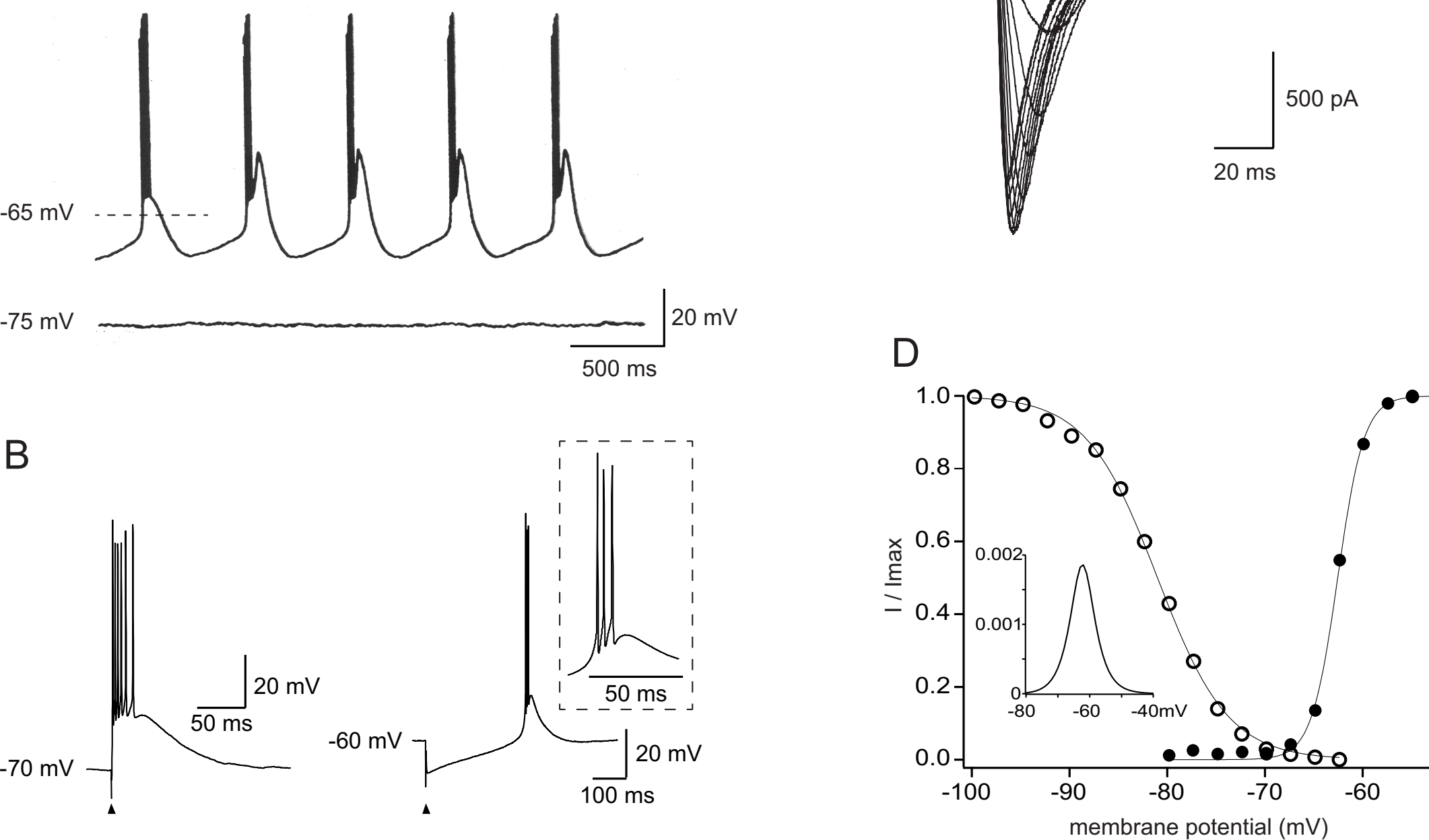
Figure 2

A

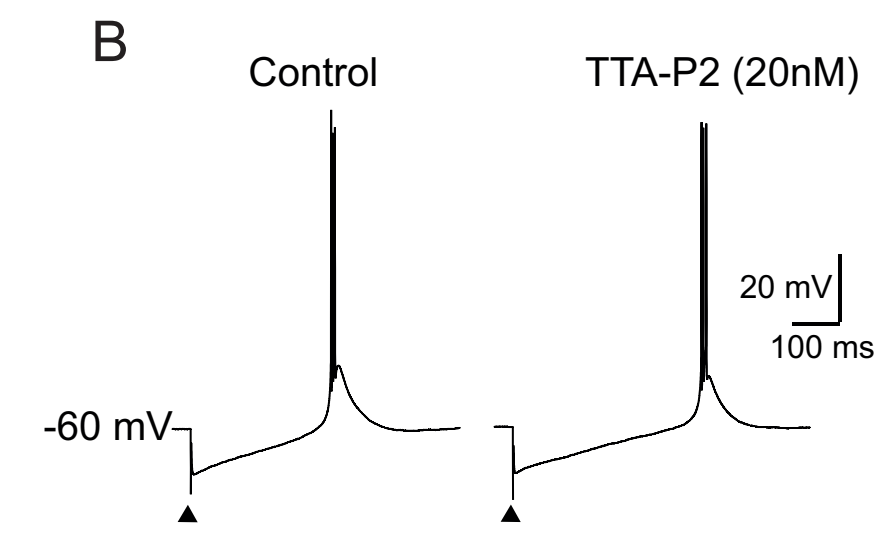

C

$50 \mathrm{~ms} \quad 100 \mathrm{~ms} \quad 300 \mathrm{~ms} \quad 500 \mathrm{~ms}$
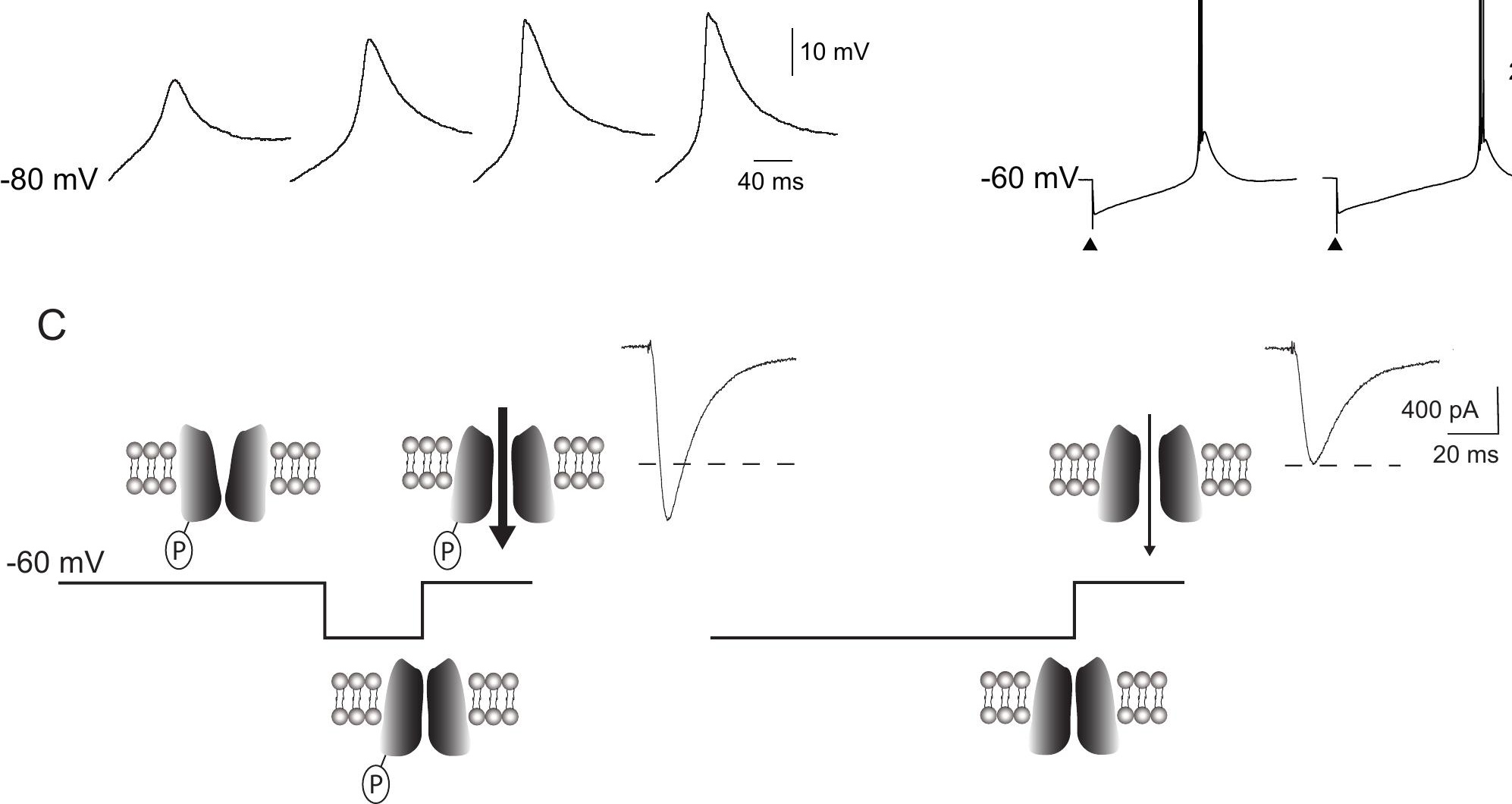
Figure 3

A

TTA-P2

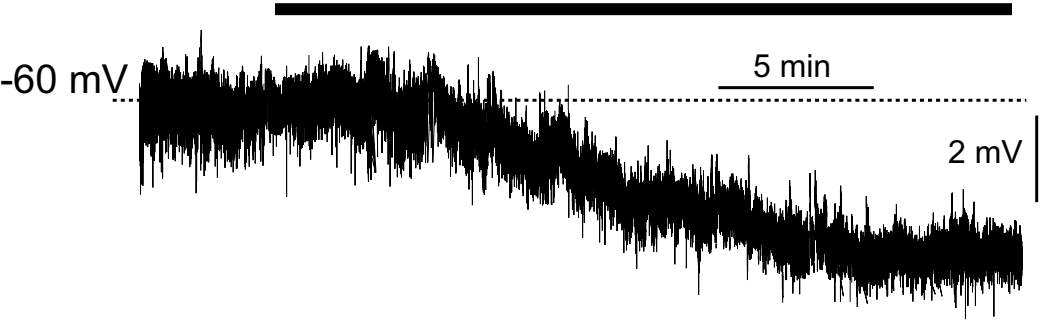

TTA-P2

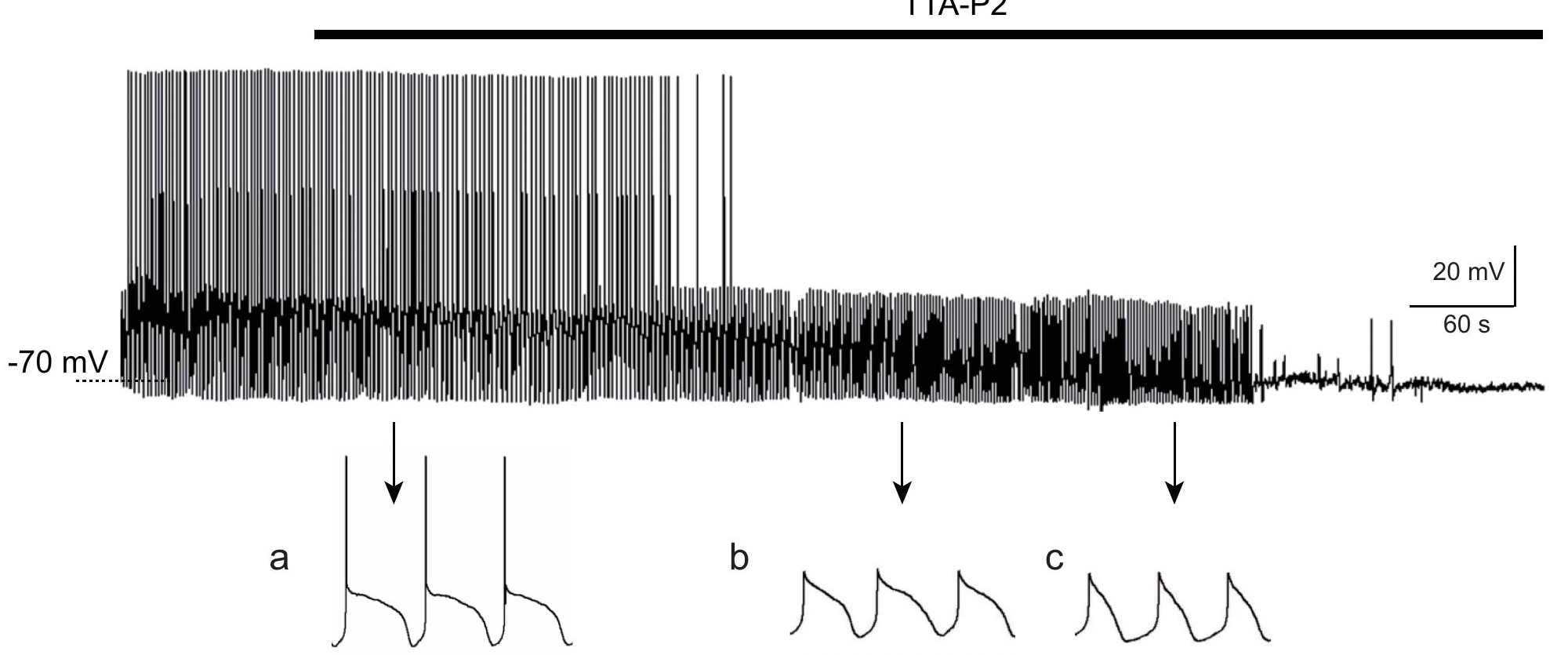

$-70 \mathrm{mV}$.

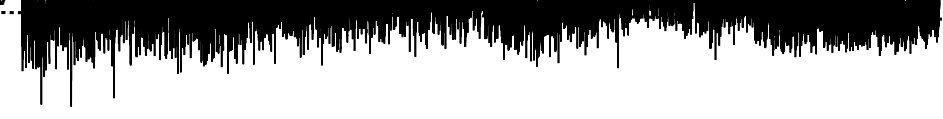


